\title{
Quizlet \& Dropbox an Easy e-Setting for Busy Teachers
}

\author{
Bui Duc Tien \\ Department of English \\ Ho Chi Minh City University of Education, HCMUE \\ Ho Chi Minh City, Vietnam \\ tienbd@hcmup.edu.vn
}

\begin{abstract}
Many teachers of English have found technology a paradise of innovative and fancy tools, yet others have come to realize how daunting it can be to rely on such considering the amount of time spent in frustration. Dropbox and Quizlet can make for an easy classroom setting using technology. Dropbox is a platform for sharing files instantly between computers and devices amongst groups of users, and Quizlet makes for easy content revision (which can be designed by both the teacher and the student). These tools facilitate feedback giving and the recycling of knowledge learnt.
\end{abstract}

Keywords - automatic syncing; content revision; Dropbox; feedback; Quizlet; sharing documents

\section{THEORETICAL \& TECHNOLOGICAL BASIS}

\section{A. Feedback}

Feedback to students' writing and speaking works is a crucial part of teaching and learning. Traditionally, feedback is provided on paper, with the teacher using normally one color ink pen (sometimes two) to underline, cross out, circle and annotate on the side bar with limited space. However, many have expressed negative opinions on the anxiety, tediousness and time-consumption this practice induces [1]; [2] .To release the burden on the part of the teacher, tools have been designed to provide automated feedback, often referred to as computer-based or computer-generated feedback, which has been proven effective in various studies [3]; [4]. However, feedback can be provided still by the teacher, but through the use of electronic devices and computer software. The use of Google Docs [5] and tablet tools [6] have pointed to the effectiveness of feedback using computers over the paper-based version.

On the technological side, Dropbox (www.dropbox.com) is a tool that helps to make feedback more convenient and effective. By nature, Dropbox enables easy file sharing amongst users, i.e. teachers and students within the educational context. What sets Dropbox off from other cloud services is its automatic synchronization between different accounts on different computers: once a new file is created on a student's laptop, it will appear immediately on the teacher's provided there is internet connection. Taking advantage of such features, the teacher can access students' written works (essays, paragraphs, reports, thesis, etc.) as well as recorded works (self-recorded speaking answers, pronunciation practice, presentations, etc.) without having to go through the downloading step. Microsoft Office Word, in particular, can be the most convenient tool for teachers to provide digital feedback in annotations and track changes, which can be viewed by students at their pleasure once Dropbox is installed. Feedback, then, becomes simple and easy for both the teacher and the student.

\section{B. The lexical approach}

ELT practitioners have recently come to agreement on certain principles regarding the teaching of vocabulary: it has to bear in mind the complexity of lexical competence, the incremental process of lexical expansion and the way items are to be stored: through association, reinforcement and exposure to the target language, which are mentioned in Stalh (1986), Nagy (1988), Blachowicz \& Fisher (2002), all as cited in reference [7], and [8]. Together these form the core beliefs of the Lexical Approach to language teaching proposed by Michael Lewis in 1993, which has not been a phenomenon but which could serve as a turning point in ELT practitioners' shift in pedagogical view, as [9] put it: "Language is grammaticalized lexis, not lexicalized grammar" (p. 34). The approach basically advocates teaching words, collocations and expressions and stresses multiple exposures as well as reinforcement of learnt vocabulary items. Though not widely supported, many authors seem to go in line with it, including [10], and especially material developers: Michael Vince, Rawdon Wyatt and Michael McCarthy in the publications regarding vocabulary enhancement, to quote a few: Advanced Language Practice [11], English Vocabulary in Use Upper-intermediate \& Advanced [12]. Check your Vocabulary for IELTS [13].

Quizlet (www.quizlet.com) serves best to attain what the lexical approach promotes: to create quizzes in a rapid and easy manner for regular recycling of knowledge, especially in vocabulary training. The fundamental rule of Quizlet quizzes is a matching of two columns: one termed TERM, the other DEFINITION. However, quizzes here are not 
restricted to term and definition exercises, but can be varied into fill-in-the-blank questions, synonym \& antonym exercises, collocation practice, and image-meaning checking. Once all input language has been made, Quizlet can automatically generate TRUE-FALSE, MULTIPLE CHOICE, and WRITTEN exercises, each time with a random order of both questions and items. Basically, an input of 5 matching columns can produce a large number of exercises, which is ideal for revision activities in light of the lexical approach.

\section{Classroom Setting FOR BUSy TEACHERS}

\section{A. Requirements}

Both the teacher and the students need to have their Dropbox and Quizlet accounts, which can be done in a few steps. Regular access to the internet is a need as content will be synced over this cyber network. Also, both teachers and students need to have proper typing, annotating and office skills in order to process files and folders quickly. Having Dropbox and Quizlet installed on mobile devices will even add to their ease of use.

\section{B. Sample setting}

In my experiment (and current practices) with Dropbox and Quizlet, I had students create their Dropbox and Quizlet accounts and install these apps on their devices (both laptops and smartphones) on the very first day of class. All this might take 10 to 20 minutes depending how clear instructions are given and how fast students deal with their devices.

To manage students' work on Dropbox, I created a classroom folder, for example WRITING INTERMEDIATE, and shared this with all my students via their accounts. In this folder I asked each student to create a sub-folder of their own, naming it after their own name. There are normally 8 to 12 students in the class, so I would have 8 to 12 sub-folders. Once this step was finished, my class was ready to use Dropbox. Students had weekly assignments on writing, which they would save onto their own Dropbox folder. For example, student A had just finished the assignment for Week 1: Writing an introduction paragraph: now he would save the file WEEK 1 as a docx. to his own sub-folder STUDENT A in the class folder WRITING INTERMEDIATE. I would see the file seconds afterwards. What I would do as a teacher is to open the file, give comments using the Track Change feature in Microsoft Office Word and any formatting tool available (like coloring, bold type \& italics, underlying, etc.). Once I had saved the file, would be visible to student A in a matter of seconds.

To get students to use Quizlet, I first created a class in my own account then added all my students using their account information. Quizlet operates on different SETS of input, so I created different sets for each class. Since creating folders in a class is not possible, I came up with a naming technique to logically organize my class content. For example, there were sets named WEEK 1.1_Definition, WEEK 1.2_Collocation, WEEK 1.3_Revision, and WEEK 2, WEEK 3, WEEK 4... were drafted in the same manner. This was to make sure students progressed from definitions to collocations to revision. I actually had a TA (teaching assistant) to create these sets of learning for my students, and I double checked the content for each set created. Students only had to access Quizlet on their mobile devices and review lessons after class.

\section{DATA}

In order to survey the effectiveness of Quizlet and Dropbox, I sent out a survey at the end of each class. The questionnaire can be found at the end of this paper.

I adopted this Likert scale to study only the opinions of the people involved, but I also conducted in-depth interviews with teachers and students to increase reliability. In the 3 classes surveyed (one with me as teacher-in-charge, and two with other teachers), there were 48 intermediate college students who were preparing for their IELTS.

\section{A. Students'feedback}

The majority of students agreed that Quizlet helped them in learning (with $30 \%$ strongly agreeing). All of the students believed Quizlet was easy to use, and $96 \%$ believed the app should be used in the future. In comparison, fewer students believed Dropbox added to their learning, with only $12 \%$ strongly agreeing. Two students out of 48 noted it was difficult to install the app, and $78 \%$ supported its future use.

In-depth interviews with 12 students revealed that Quizlet was most effective in enhancing students' collocational competence (with most of them practicing time after time to reach a perfect score). Five said that Quizlet would be more effective with images. For Dropbox, all the interviewees acknowledged the ease of use, and that they found feedback on docx. files more detailed and focused than written forms. They also commented on the fact that Dropbox made feedback more readily accessible than emails did.

\section{B. Teachers'feedback}

The two other teachers strongly agreed to all the three statements. They further explained that giving feedback on a computer was certainly better than hand-written annotations since they could easily color mistakes and highlight different types of errors. Dropbox made it even more convenient since the download step became obsolete. Quizlet, by means of comparison, was the most user-friendly quiz maker they had ever used, and they even found their own knowledge enhanced after using the app themselves. 


\section{CONCLUSION}

Based on my action research with the three classes, there is strong evidence to support the use of Dropbox and Quizlet in the English classroom. As technological tools, these support the process of giving feedback on the part of the teacher, and revising lessons on the part of the learner. However, there needs to be more research in large classes and in different skills and aspects of language teaching.

\section{REFERENCE}

[1] Hyland. K, Providing productive feedback. ELT Journal, 44(4), 279285. http://dx.doi.org/10.1093/elt/44.4.279, 1990

[2] Hairston. M, On not being a composition slave. In C. Bridges, Training the new teacher of college composition (pp. 117124). Urbana, IL: NCTE, 1986

[3] Chen. J, Computer Generated Error Feedback and Writing Process: A Link. TESL-EJ, 2(3), 1-19. Retrieved from http://www.cc.kyotosu.ac.jp/information/tesl-ej/ej07/a1.html, 1997

[4] Ware. P, Computer-Generated Feedback on Student Writing. TESOL Quarterly, 45(4), 769-774. http://dx.doi.org/10.5054/tq.2011.272525, 2011

[5] Zheng, B., Lawrence, J., Warschauer, M., \& Lin, C, Middle School Students' Writing and Feedback in a Cloud-Based Classroom Environment. Technology, Knowledge And Learning, 20(2), 201-229. http://dx.doi.org/10.1007/s10758-014-9239-z, 2014

[6] Denison, A., Bate, E., \& Thompson, J, Tablet versus paper marking in assessment: feedback matters. Perspectives On Medical Education, 5(2), 108-113. $\quad$ http://dx.doi.org/10.1007/s40037-016$\underline{0262-8}, 2016$

[7] Padak, N, What's IN a word? Teaching Vocabulary from the Inside Out. New England Reading Association Journal, 8-11, 2006

[8] Schmitt. P, Researching Vocabulary. Basingstoke: Palgrave Macmillan, 2002

[9] Lewis. M, The Lexical Approach: The State of ELT and a Way Forward. Hove, England: Language Teaching Publications, 1993

[10] Nattinger, J., \& DeCarrico, J, Lexical phrases and language teaching. Oxford [England]: Oxford University Press, 1992

[11] Vince, M., \& Sunderland, M, Advanced language practice. Oxford: Heinemann, 2003

[12] McCarthy. M., \& O'Dell. F, English vocabulary in use. Cambridge: Cambridge University Press, 1994

[13] Wyatt, R, Check Your Vocabulary For English For The IELTS Examination. London: Peter Collin, 2002 